\title{
Immunohistochemical expression of four different stem cell markers in prostate cancer: High expression of NANOG in conjunction with hypoxia-inducible factor-1 $\alpha$ expression is involved in prostate epithelial malignancy
}

\author{
KATSUHITO MIYAZAWA ${ }^{1}$, TAKUJI TANAKA ${ }^{2}$, DAN NAKAI $^{1}$, NOBUYO MORITA $^{1}$ and KOJI SUZUKI ${ }^{1}$ \\ ${ }^{1}$ Department of Urology, Kanazawa Medical University, Uchinada, Ishikawa 920-0293; \\ ${ }^{2}$ Department of Diagnositic Pathology and Research Center of Diagnostic Pathology, Gifu Municipal Hospital, \\ Gifu, Gifu 500-8513, Japan
}

Received August 25, 2013; Accepted May 23, 2014

DOI: $10.3892 / 01.2014 .2274$

\begin{abstract}
Cancer stem cells (CSCs) have been identified in a variety of cancer types, including prostate cancer. The aim of the present study was to evaluate the immunohistochemical expression of NANOG, octamer 4 (OCT4), cluster of differentiation 133 (CD133) and NESTIN, which are all CSC markers, and assess their function in prostate carcinogenesis. A total of 114 patients were referred to the Kanazawa Medical University Hospital (Uchinada, Japan) having presented with elevated serum prostate-specific antigen levels and/or abnormal digital rectal examinations, and underwent transrectal ultrasound sonography guided eight core biopsies. The prostate pathological specimens were re-evaluated for selection in this study. When specimens were diagnosed as prostate cancer, immunohistochemical analysis of the four different stem cell markers (NANOG, OCT4, CD133 and NESTIN) and hypoxia-inducible factor (HIF)- $1 \alpha$ was performed. Prostate cancer was found in 38 cases $(33.3 \%)$, while the other patients had benign prostate hyperplasia with prostatitis. All prostate cancers were histopathologically identified as adenocarcinomas of various grades, and cancer cells and intraepithelial neoplasia (high grade) were immunohistochemically shown to express NANOG and OCT4, but not CD133 and NESTIN. The intensity of NANOG expression was much greater than that of OCT4, and the positivity and intensity of the four stem cell markers, including NANOG, were elevated with high Gleason scores. A significant correlation was observed between the NANOG- and HIF-1 $\alpha$-positive regions. The CSC markers, in particular OCT4 and NANOG, were immunohistochemically
\end{abstract}

Correspondence to: Professor Katsuhito Miyazawa, Department of Urology, Kanazawa Medical University, 1-1 Daigaku, Uchinada, Ishikawa 920-0293, Japan

E-mail: miyazawa@kanazawa-med.ac.jp

Key words: cancer stem cell, NANOG, OCT4, prostate cancer, hypoxia-inducible factor- $1 \alpha$ expressed in prostate cancers. Furthermore, HIF-1 $\alpha$ expression may affect NANOG and/or OCT4 expression. The findings of the current study suggested that NANOG expression may be a biomarker for the diagnosis of prostate cancer, and the coexpression of NANOG and HIF-1 $\alpha$ may be involved in prostate carcinogenesis.

\section{Introduction}

Prostate cancer is the second leading type of malignancy in males in North America with an estimated 186,320 new cases and 28,660 mortalities reported in 2008 (1). The number of patients with prostate cancer has also been increasing in Japan (2). Alterations in nuclear morphometry, gene and protein expression, gene promoter methylation and angiogenesis are known to be involved in prostate carcinogenesis and contribute to field cancerization in the prostate (3).

Our understanding of carcinogenesis has been enhanced by the recently revived cancer stem cell (CSC) theory. CSCs have been reported in multiple solid tumors in different tissues, including the prostate (4-6). CSCs are endowed with high tumorigenic capacity and may drive tumor formation, maintain tumor homeostasis and mediate tumor metastasis. A number of primary non-malignant and malignant tumor-derived human prostate epithelial cell lines have been developed using a retroviral vector encoding human telomerase reverse transcriptase. These cell lines exhibit the characteristics of stem cells and express embryonic stem (ES) cell markers, such as NANOG, octamer 4 (OCT4) and SRY-box 2 (Sox-2), as well as the early progenitor cell markers, cluster of differentiation 133 (CD133), CD44 and NESTIN $(7,8)$.

The multipotent stem cell marker NANOG was identified in $2003(9,10)$. NANOG is specifically expressed in the human embryonic pluripotent stem cells of embryos prior to or following implantation, primordial germ cells, ES cells cultured in vitro, embryonic germ cells and embryonic carcinoma cells, and functions in the promotion of cell proliferation. NANOG is expressed in dysgerminoma and embryonic carcinoma, but not in immature teratoma, endodermal sinus tumors 
or choriocarcinoma (11). NANOG can be used to distinguish between germ cell tumors and non-germ cell tumors (11). NANOG has also been found to be a sensitive and specific marker of metastatic germ cell tumors $(11,12)$. With regard to prostate cancer, several studies have recently suggested the positive reaction of adenocarcinoma (ADC) cells against NANOG $(13,14)$. Therefore, NANOG is an emerging focus in developmental biology, due to its importance in the maintenance of self-renewal and multipotential capacity in a variety of malignancies, including prostate cancer. Octamer 4 (OCT4) belongs to the family of Pit-Oct-Unc-domain transcription factors and has been found in ES and germ cells (15). A number of reports have shown that OCT4 is pivotal in maintaining the self-renewal and pluripotency of ES cells (16). Recently, it has also been shown that cancer cells expressing OCT4 and Sox 2 may be crucial in cancer development (17). The two genes, Sox 2 and OCT4, are part of an important gene regulatory network, and are essential for embryogenesis and the pluripotency and self-renewal of cells (16). Previous studies have also suggested that certain cancers, including prostate cancer $(14,18)$, express Sox 2 and OCT4 simultaneously $(19,20)$, and their expression has been associated with the differentiation of tumors (21). These two genes are significant for cancer cell survival. CD133 is a transmembrane glycoprotein that is originally expressed in a subset of stem cells in the hematopoietic system as well as in the solid tumors of other tissues (22), including the prostate (23). CD133-positive cancer cells have cancer stem/progenitor cells that exhibit resistance to cancer therapies (including radiation and chemotherapy), a greater invasion ability and metastasis in various malignancies. Thus, the utility of CD133 expression as a prognostic marker has been suggested (22), as well as in the prostate (23). NESTIN is an intermediate filament protein that is known to be important as a neural stem cell marker (24). However, the expression of NESTIN has recently been reported to be associated with the proliferation of progenitor cell populations within neoplasms (25). In addition, the upregulation of NESTIN has been found to closely correlate with the malignancy and metastasis of a variety of malignancies (25), including prostate cancer (26).

The expression of NANOG, OCT4, Sox, NESTIN and CD44 has been observed in human prostate ADC cells (7), which suggests the importance of cancer stem and progenitor cells in prostate carcinogenesis. However, OCT4A-expressing cells have rarely been identified in human benign and malignant prostate glands (27). The number of OCT4A-expressing cells has been shown to increase in prostate ADC with high Gleason scores (27). OCT4A-expressing cancer cells have also been shown to coexpress Sox2, an ES cell marker, but did not express other putative stem cell markers, such as NANOG and CD133 (27). The neuroendocrine differentiation markers, chromogranin A and synaptophysin, are also coexpressed by the majority of OCT4A-expressing cells (27). Thus, discrepancies exist in reports investigating the role and expression of certain stem and progenitor cell markers in prostate cancer cells.

In the current study, in order to determine whether certain stem cell markers may be used for the diagnosis of prostate cancer, the immunohistochemical expression of NANOG, OCT4, CD133 and NESTIN, which are well-known stem cell markers, were investigated in 38 cases from a total of
114 biopsy specimens obtained from Japanese patients with prostate cancer between January 2011 and December 2011. In addition, the correlation between the expression of these stem cell markers in prostate cancer and non-cancerous tissues was evaluated. Hypoxia has been associated with an aggressive course and poor clinical outcome of cancer $(28,29)$; low oxygen may promote the self-renewal of CSCs $(14,30-32)$. Therefore, the immunohistochemical expression of hypoxia-inducible factor (HIF)-1 $\alpha$ was also examined.

\section{Materials and methods}

Study samples. Between October 2010 and September 2011, a total of 114 patients with elevated serum prostate-specific antigen levels of $>4 \mathrm{ng} / \mathrm{ml}$ and/or abnormal digital rectal examinations were referred to the Kanazawa Medical University Hospital (Uchinada, Japan) and underwent transrectal ultrasound sonography-guided eight-core biopsies. Histopathological diagnosis was re-evaluated by a certified pathologist on hematoxylin and eosin-stained sections from the biopsy samples. Prior to this study, written informed consent was obtained from all patients. The study was approved by the Ethics Committee of Kanazawa Medical University (Uchinada, Japan), and the Declaration of Helsinki regarding the use of human tissue was strictly followed.

Immunohistochemistry. Serial sections, $4 \mu \mathrm{m}$ in thickness, prepared from formalin-fixed, paraffin-embedded specimens, were available for immunohistochemical analysis. Sections were deparaffinized and rehydrated following standard methods. Briefly, the sections were deparaffinized three times with xylene for 5 mins, and rehydrated in graded ethanol (80-100\%) for 5 mins. A microwave antigen retrieval procedure was performed for $20 \mathrm{~min}$ in citrate buffer ( $\mathrm{pH}$ 6.0) and hydrogen peroxide was used to block non-specific peroxidase reactions. Following washing with phosphate-buffered saline (PBS, $\mathrm{pH}$ 7.4), sections were incubated with rabbit polyclonal anti-human NANOG (ab21624; 1:30 dilution; Abcam, Cambridge, MA, USA), OCT4 (ab18976; 1:100 dilution; Abcam), CD133 (ab19898; 1:200 dilution; Abcam) and NESTIN (ab93666; 1/120 dilution; Abcam), as well as mouse monoclonal anti-human HIF-1 $\alpha$ (ab10625; 1:200 dilution; Abcam). Following washing three times with PBS, sections were incubated at $37^{\circ} \mathrm{C}$ with biotin-conjugated goat anti-rabbit polyclonal antibody (ab6720; Abcam) for $20 \mathrm{~min}$. Visualization was achieved by incubation with diaminobenzidine for $10 \mathrm{~min}$ and slides were counterstained with Mayer hematoxylin. Following hydration in graded alcohol and clearing with xylene, the slides were mounted with neutral gum. Seminomas obtained from testicular cancer specimens of two patients (Kanazawa Medical University Hospital) who had undergone surgical resection, which had been confirmed to overexpress NANOG and OCT4, were selected as the appropriate positive controls (33), and paraffin-embedded Caco-2 cells (cat. no. CRL-2102; American Type Culture Collection, Manassas, VA, USA) and endothelial cells in ADC obtained from colorectal cancer specimens of two patients (Kanazawa Medical University Hospital) who had undergone surgical resection were used as internal positive controls for CD133 and NESTIN $(34,35)$. Negative 
controls were prepared by incubating samples without the primary antibody. The intensity of immunoreactivity against all the primary antibodies used was assessed using a microscope (Olympus BX41; Olympus Optical, Tokyo, Japan). Indices were determined by counting the number of positive nuclei among $\geq 300$ cells in high-power fields, and were indicated as percentages. Positive cells were evaluated for their intensity of immunoreactivity on a 0 or $3+$ scale. The overall intensity of the staining reaction was scored as follows: 0 , no immunoreactivity and no positive cells; 1 (+/-), weak expression in $<50 \%$ cells; $2(+)$, moderate expression in $\geq 50 \%$ cells; $3(++)$, moderate to strong expression in $51-75 \%$ cells; and $4(+++)$, strong and diffuse expression in $>76 \%$ cells. Slides were reviewed by one pathologist blinded to the clinical data.

Statistical analysis. Incidences among the groups were compared using a two-tailed unpaired t-test and Bonferroni multiple comparison test (GraphPad InStat version 3.05; GraphPad Software, San Diego, CA, USA). P $<0.05$ was considered to indicate a statistically significant difference between the groups.

\section{Results}

General observations. Prostate cancer was found in 38 (33.3\%) of 114 males who underwent eight core biopsy and were divided into two subgroups according to the following Gleason scores: 30 cases with $<6(3+3)$ and eight cases with $>7(3+4)$, as shown in Fig. 1A-C. Other specimens were diagnosed as benign prostate hyperplasia with marginal prostatitis (Fig. 1D) or normal prostate glands (Fig. 1E).

Immunohistochemical findings. Of the four stem cell markers, ADC cells in all specimens of the 38 cases of prostate ADC were found to positively express the NANOG (Fig. 2A) and OCT4 (Fig. 2B) proteins. However, the immunohistochemical expression of CD133 (Fig. 2C) and NESTIN (Fig. 2D) was extremely weak or absent in the cancer cells of prostate ADC and those of non-cancerous cells. High-grade prostate intraepithelial neoplasia (PIN) was positive for NANOG (Fig. 2E) and OCT4 (Fig. 2F); however, the number of positive cells was fewer than that of prostate cancer. The majority of hyperplastic glands were negative for NANOG (Fig. 2I) and OCT4 (Fig. 2J) staining. The cells of hyperplastic glands were completely negative for CD133 (Fig. 2K) and NESTIN (Fig. 2L). Positive reactions for NANOG and OCT4 were predominantly localized in the nuclei of cancer cells and the cell nuclei of PIN. The staining intensity of NANOG was stronger than that of OCT4.

Fig. 3 shows the scorings for the immunohistochemical expression of the four different stem cell markers in prostate cancer and non-cancerous cells. The immunoreactivities of NANOG $(\mathrm{P}<0.001)$ and OCT4 $(\mathrm{P}<0.01)$ in prostate cancer was significantly greater than those in the non-cancerous cells. No significant differences were identified between the immunoreactivities of CD133 and NESTIN in the prostate cancer and non-cancerous cells. Based on the detailed analysis, the scoring data for the four different stem cell markers in the non-cancerous and prostate cancer cells are also illustrated in Figs. 4 and 5, respectively. The immunohistochemical intensity of prostate cancer was weakest for NANOG followed by
OCT4, with the strongest staining for CD133 and NESTIN. In the non-cancerous tissue, as shown in Fig. 4, the immunoreactivities of NANOG $(\mathrm{P}<0.001)$ and OCT4 $(\mathrm{P}<0.001)$ were significantly greater than those of CD133 and NESTIN. In prostate cancer, NANOG $(\mathrm{P}<0.001)$ immunoreactivity was the strongest among the four stem cell markers (Fig. 5).

The expression score for NANOG in the prostate cancer cells was significantly greater than that of cells in high-grade PIN and the hyperplastic glands $(\mathrm{P}<0.001$ for each comparison; Fig. 6). The number of atypical cells in high-grade PIN was also higher than that in the hyperplastic glands $(\mathrm{P}<0.001$; Fig. 6). The expression of NANOG, OCT4, CD133 and NESTIN in prostate ADCs with high Gleason scores $(>3+4)$ was greater than that in prostate cancers with low Gleason scores $(<3+3)$, although this difference was not significant (Fig. 7).

HIF-1 $\alpha$ immunohistochemistry revealed that specific cancer cell nuclei (Fig. 8A and B), corresponding to their Gleason score, as well as a few cell nuclei in high-grade PIN showed a positive reaction for HIF-1 $\alpha$ (Fig. 8C). However, hyperplastic and normal glandular cells were negative for HIF-1 $\alpha$ (Fig. 8D). The mean score for HIF-1 $\alpha$ with a high Gleason score was significantly greater than that of HIF-1 $\alpha$ with a low Gleason score $(\mathrm{P}<0.001$; Fig. 7$)$.

\section{Discussion}

Pluripotency-associated transcription factors, including NANOG, Sox 2 and OCT4, are known as regulators of cellular identity in ES cells (36) and have recently been identified in the epithelial malignancies of a variety of tissues $(33,37)$, including prostate cancer $(13,14,18)$. CD133 (23) and NESTIN (26) have also been reported to be expressed in prostate cancer. However, these reports were predominantly from human prostate cancer cell lines. Consistent with their role in sustaining the stemness of ES cells, pluripotency-related factors have been suggested to be expressed at a higher frequency in cancer exhibiting lower degrees of differentiation (37). In this study, the immunohistochemical expression of NANOG was markedly higher than that of the other stem cell markers, OCT4, CD133 and NESTIN. The reason for the discrepancy between the findings of the current study and those reported by others is not known; however, differences between prostate cancer obtained from biopsy specimens and human prostate cancer cell lines may have influenced the stainability of the four different stem cell markers, NANOG, OCT4, CD133 and NESTIN. Although Miki et al (8) observed tumor compartments and high-grade PIN with higher CD133 and an inverse correlation with androgen receptor staining, a CD133-positive reaction was not detected in the prostate cancer cells, PIN or hyperplastic glandular cells in this study.

CSCs comprise of $\sim 0.01 \%$ of the tumor cell population. In this study, a large number of strongly positive NANOG and/or OCT4 cancer cells were observed. This high level of expression is not necessarily associated with stem cell behavior, but rather to the deregulation proteins that provide some type of growth advantage to cancer cells (38-41).

Androgen deprivation-induced atrophy of the prostate gland and subsequent regeneration following androgen replacement have indicated that the stem cell population may reside in the adult prostate gland in rodents (42). The origin 

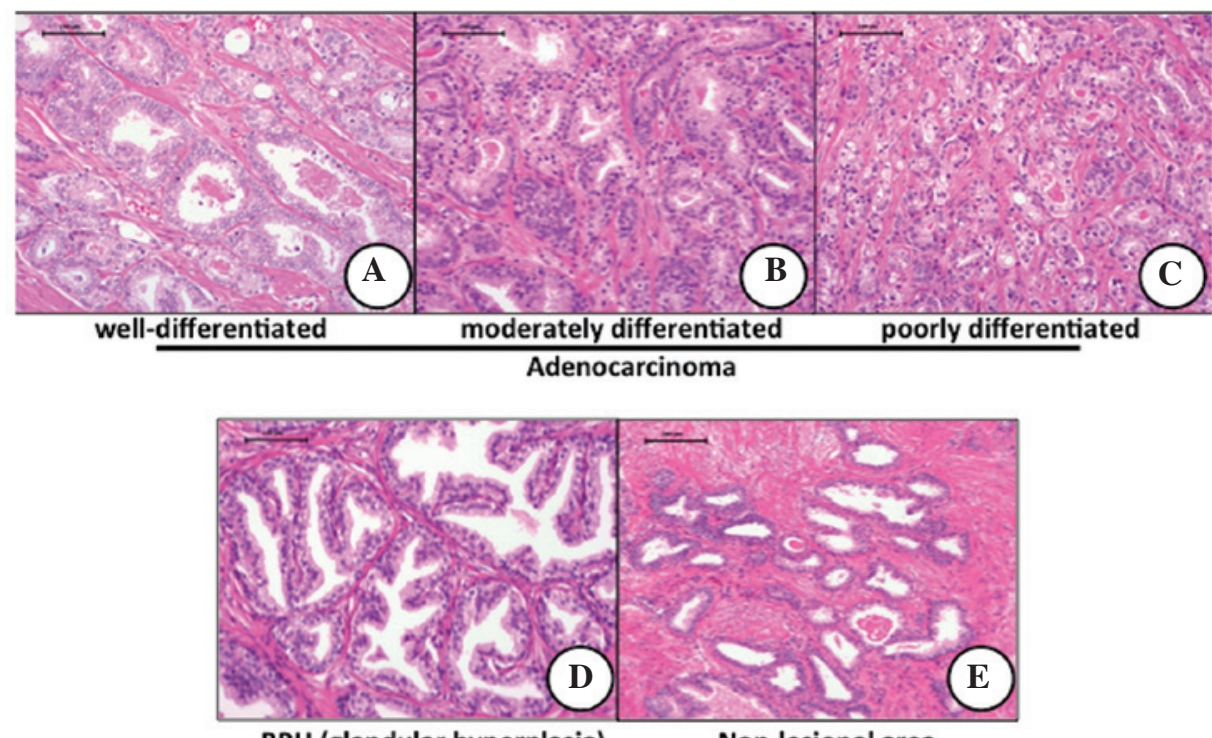

BPH (glandular hyperplasia)

Non-lesional area

Figure 1. Histopathology of biopsy specimen. Prostate biopsy specimen: (A-C) Adenocarcinoma (magnification, x100), (D) benign prostate (glandular) hyperplasia and (E) non-lesional area (magnification, x200). Gleason scores: (A) 2+2; (B) 3+3 and (C) 4+4 (hematoxylin and eosin stain; scale bars, $100 \mu \mathrm{m}$ ).
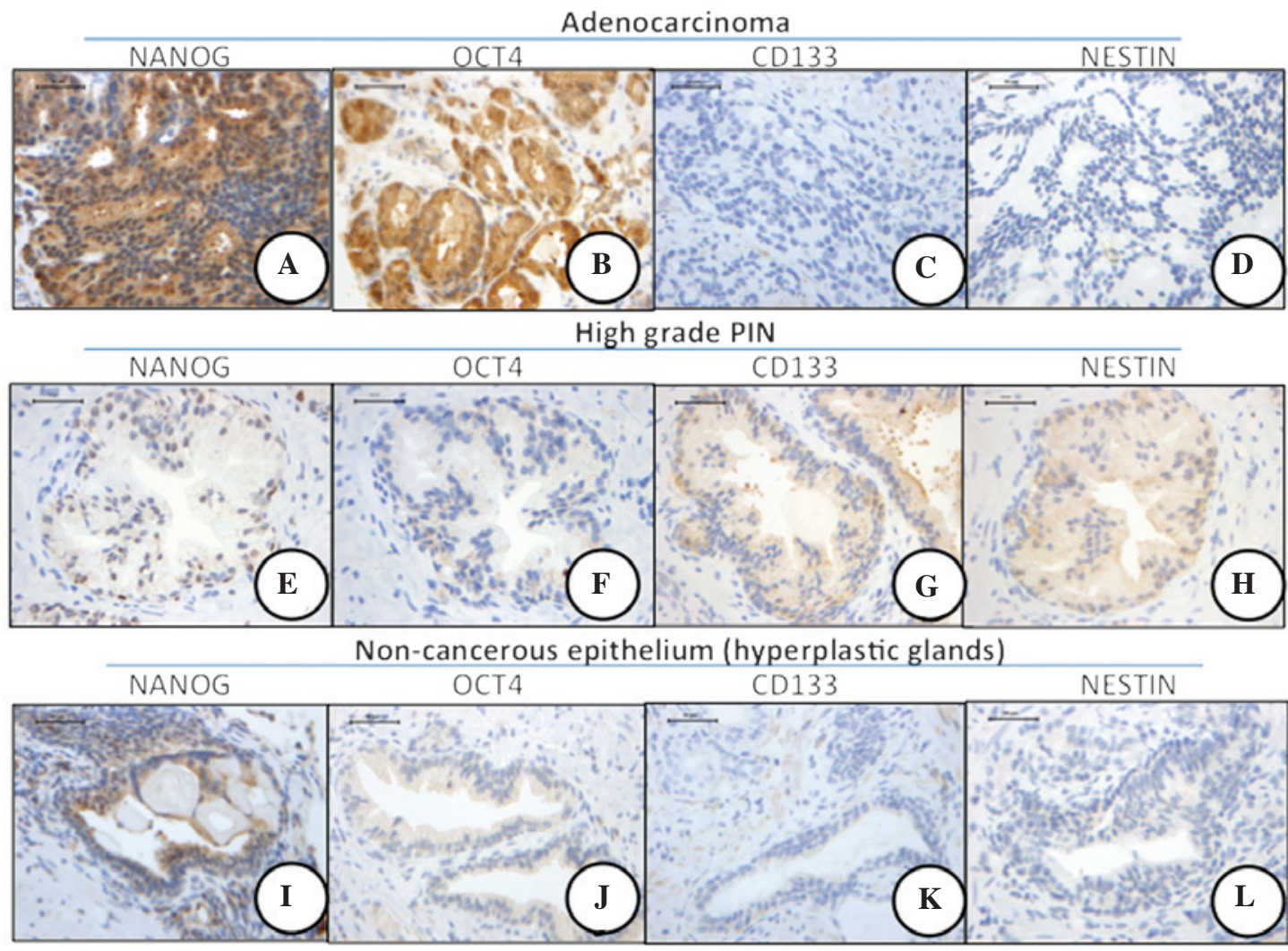

Figure 2. Immunohistochemistry of four stem cell markers in prostate adenocarcinoma and non-cancerous epithelium. NANOG and OCT4 proteins were mainly localized in the nucleus and cytoplasm of the tumor cells of prostate cancer. (A) NANOG expression was strong in cancer cell nuclei, while (E) OCT4 expression was weak (magnification, x200; scale bars, $50 \mu \mathrm{m}$ ). OCT4, octamer 4.

of prostate cancer remains unknown and has given rise to a series of hypotheses (43). Prostate ADCs are frequently multifocal, show the same immunohistochemical profile as benign glandular cells, and lack basal cell markers, such as p63 and cytokeratin $34 \beta$. This indicates that prostate cancer may develop from altered benign glandular cells. However, multiple pluripotency markers, such as CD44, CD117 and Oct3/4, have been shown to be expressed in prostate cancer, indicating that prostate cancer may develop from common stem cell-like or intermediate cells $(8,44)$. The findings on the expression of NANOG described in the current study may also support this hypothesis. 


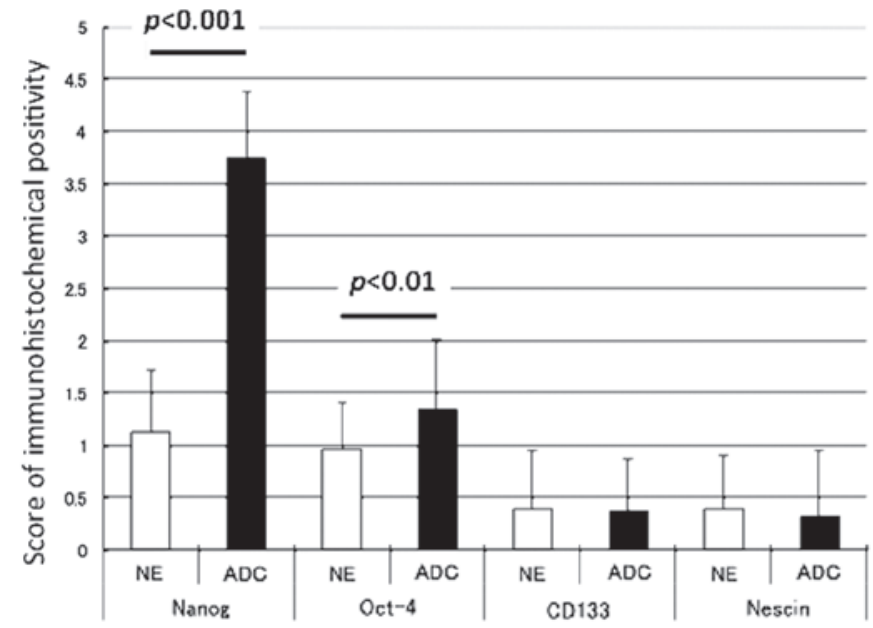

Figure 3. Immunohistochemical expression scores of four stem cell markers in prostate ADC and NE. The scores of NANOG and OCT4 in ADC were significantly higher than that in the $\mathrm{NE}(\mathrm{P}<0.001$ and $\mathrm{P}<0.01$, respectively). ADC, adenocarcinoma; NE, non-cancerous epithelium; OCT4, octamer 4.

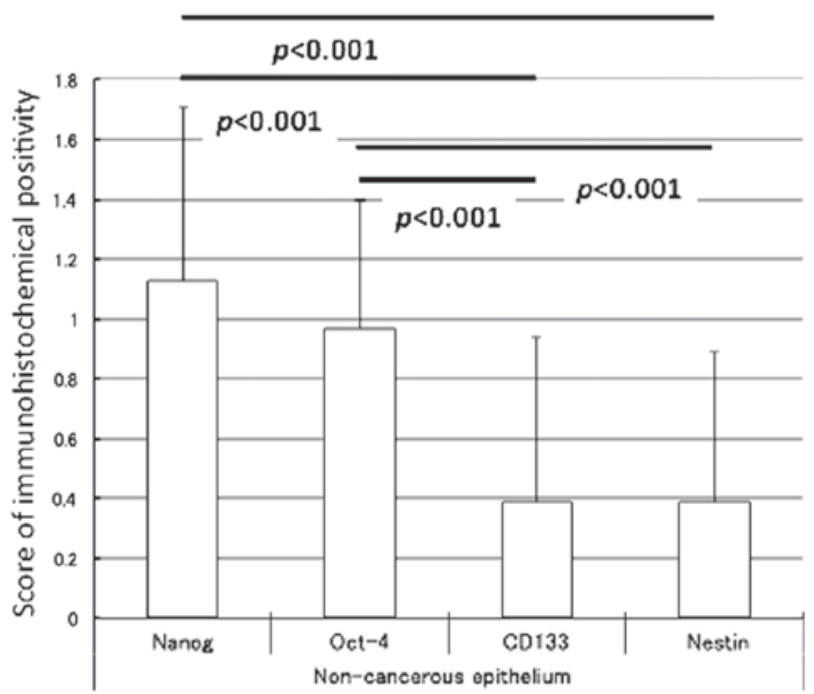

Figure 4. Immunohistochemical expression scores of four stem cell markers in non-cancerous epithelium. The scores of NANOG and OCT4 were higher than those of CD133 and NESTIN $(\mathrm{P}<0.001)$. No significant difference was identified between the scores of NANOG and OCT4. OCT4, octamer 4; CD133, cluster of differentiation 133 .

NANOG $(9,10)$ is one of the four factors known to reprogram adult cells into germline-competent induced pluripotent stem cells (45). NANOG is also critical in maintaining the self-renewal and pluripotency of ES cells by regulating the cell fate of the pluripotent inner cell mass (46-48). Notably, elevated NANOG protein expression in several types of human cancer has been reported, predominantly in germ cell tumors, as well as the malignancies of non-germ cells (38), suggesting the involvement of NANOG in tumorigenesis and progression. Non-germ cell tumors, including breast (38) and oral cancer (49), also express NANOG. A systematic study using animal models and in vitro cell systems has provided substantial evidence for the key function of NANOG in human tumor development (50). A recent study has shown that the transforming growth factor (TGF)- $\beta$ pathway is involved in

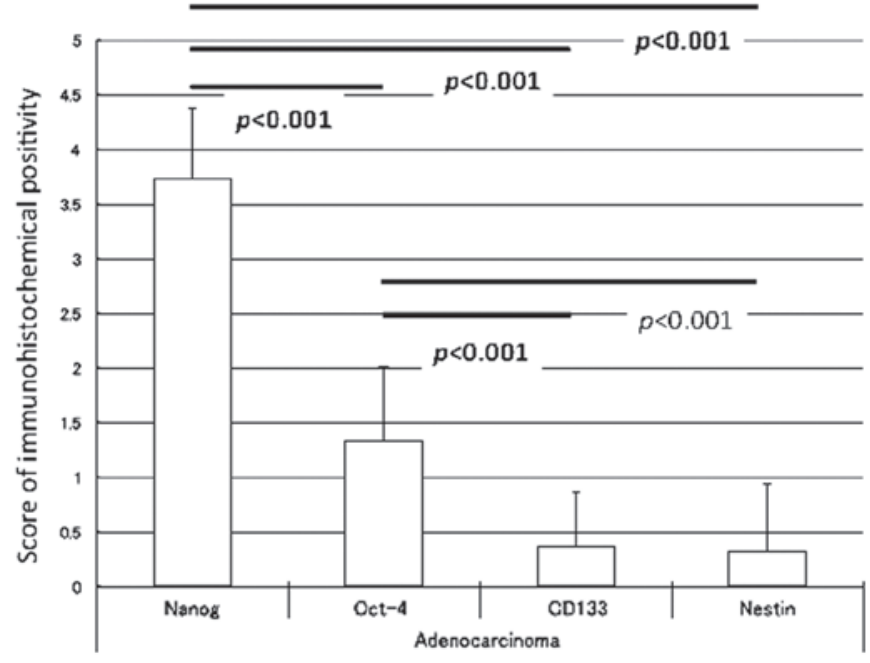

Figure 5. Immunohistochemical expression scores of four stem cell markers in prostate adenocarcinoma. The score of NANOG was the highest among the four stem cell markers, and the value was significantly greater than that of OCT4 $(\mathrm{P}<0.001), \mathrm{CD} 133(\mathrm{P}<0.001)$ and NESTIN $(\mathrm{P}<0.001)$. The score of OCT4 was significantly higher than that of CD133 $(\mathrm{P}<0.001)$ and nestin $(\mathrm{P}<0.001)$. OCT4, octamer 4; CD133, cluster of differentiation 133.

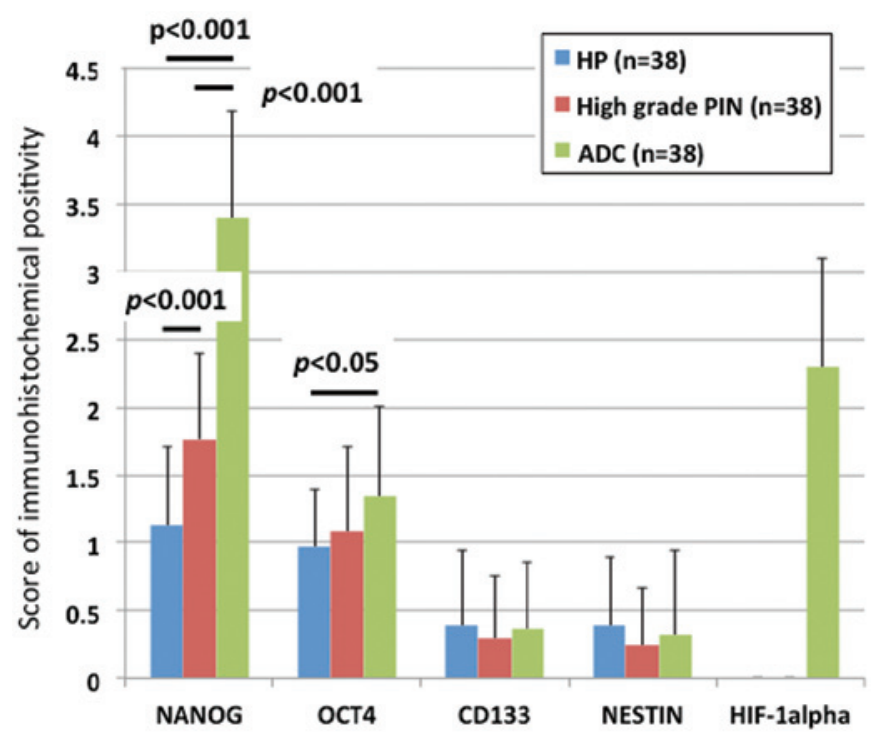

Figure 6. Immunohistochemical scores of four stem cell markers and HIF-1o in the hyperplastic glands (benign prostate hyperplasia), high-grade PIN and prostatic ADC. The score of NANOG in ADC was significantly greater than that of the hyperplastic glands $(\mathrm{P}<0.001)$ and high-grade PIN $(\mathrm{P}<0.001)$; the value of high-grade PIN was significantly higher than that of hyperplastic glands $(\mathrm{P}<0.001)$. The score of OCT4 in ADC was significantly higher than that in the hyperplastic glands $(\mathrm{P}<0.05)$, while the scores of $\mathrm{CD} 133$ and NESTIN of three lesions (hyperplastic glands, high-grade PIN and ADC) were almost similar. HIF- $1 \alpha$ was expressed in the nuclei of ADC, but not in the hyperplastic glands and high-grade PIN. HP, hyperplastic; ADC, adenocarcinoma; HIF-1 $\alpha$, hypoxia-inducible factor- $1 \alpha$; PIN, prostate intraepithelial neoplasia; OCT4, octamer 4; CD133, cluster of differentiation 133.

the regulation of NANOG gene expression via binding with the NANOG proximal promoter (51). TGF- $\beta$ functions as a key tumor suppressor of the prostate and can also promote malignant progression and metastasis of the advanced disease (52). Human cultured prostate cancer cells, prostate cancer xenografts and primary prostate cancer cells express a functional 
A

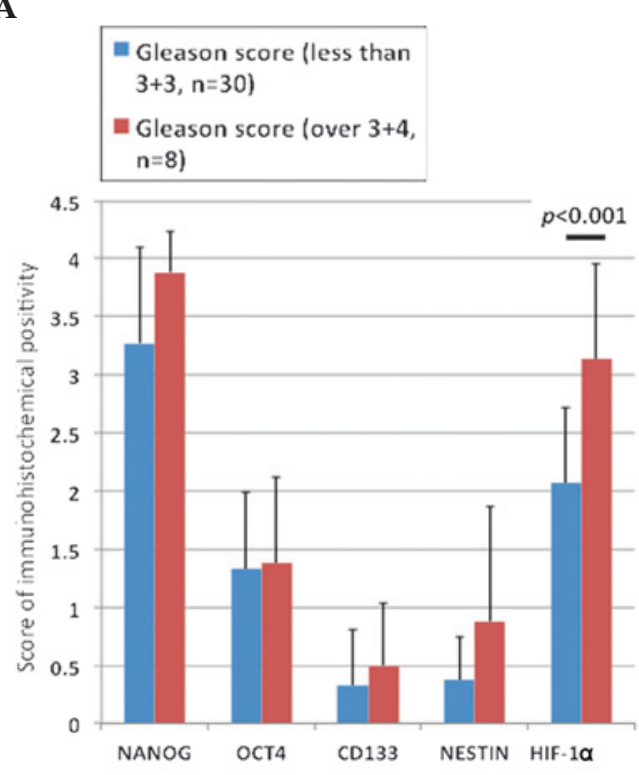

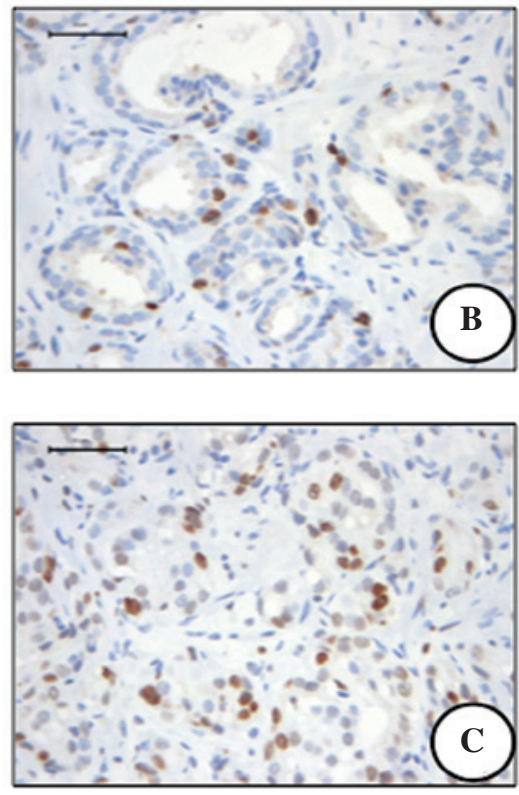

Figure 7. (A) Immunohistochemical scores of four stem cell markers and HIF-1 $\alpha$ in prostatic ADC with Gleason scores of $<3+3$ and $>3+4$. No significant differences were identified between the scores of NANOG, OCT4, CD133 and NESTIN in the two different Gleason score groups. However, the score of HIF-1 $\alpha$ was greater in ADC with Gleason scores of $>3+4$ than that in ADC with Gleason scores of $<3+3(\mathrm{P}<0.001)$. The number of NANOG-positive cancer cells in (B) high Gleason score groups (3+4) was greater than that of (C) low Gleason score groups (2+2) (magnification, 200; scale bars, $50 \mu \mathrm{m}$ ). ADC, adenocarcinoma; HIF-1 $\alpha$, hypoxia-inducible factor-1 $\alpha$; OCT4, octamer 4; CD133, cluster of differentiation 133.
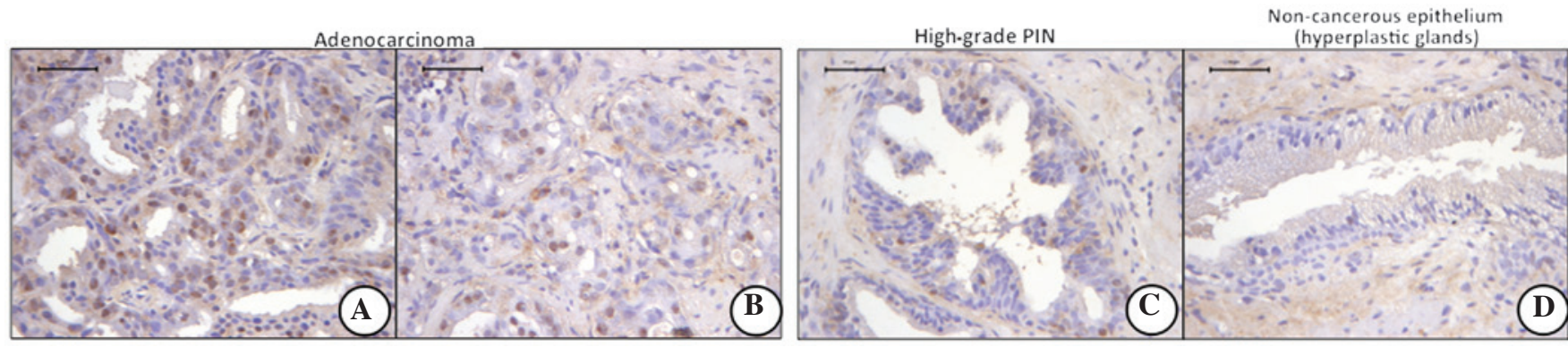

Figure 8. HIF-1 $\alpha$ immunohistochemistry in ADC, high-grade PIN and hyperplastic glands. The number of HIF-1 $\alpha$-positive nuclei of (A and B) ADCs was greater than in (C) high-grade PIN. The number of HIF-1 $\alpha$-positive nuclei of (B) ADCs with Gleason scores of $>3+4$ was larger than that of (A) ADCs with Gleason scores of $<3+3$. No positive cell nuclei for HIF-1 $\alpha$ were identified in the hyperplastic glandular cells (magnification, $\mathrm{x} 200$; scale bars, $50 \mu \mathrm{m}$ ). ADC, adenocarcinoma; HIF-1 $\alpha$, hypoxia-inducible factor-1 $\alpha$.; PIN, prostate intraepithelial neoplasia.

variant of NANOG, NANOG mRNA, in cancer cells (50). This expression is derived predominantly from a retrogene locus termed NANOGp8 (50). In this study, the NANOG protein was detected in the nucleus of cancer cells, but was not expressed in hyperplastic glandular cells. These findings suggest that NANOG has a particular function in prostate cancer development. In addition, a significant correlation has been reported between NANOG-, OCT4- and HIF-1 $\alpha$-positive regions (31). Low oxygen levels promote self-renewal in stem cells and hypoxia has been associated with an aggressive disease course and poor clinical outcomes in malignancies, including prostate cancer $(28,29)$. Furthermore, a number of aggressive neoplasms exhibit gene expression signatures characteristic of human ES cells. Thus, HIF may act as a key inducer of a dynamic state of stemness in pathological conditions.

OCT4 maintains pluripotency in embryogenesis; the upregulation of OCT4 results in differentiation to the primitive endoderm and mesoderm, while downregulation induces a loss of pluripotency and dedifferentiation into the trophectoderm (53). A recent report questioned the function of OCT4 as a pure stem cell marker by showing its expression in differentiated cells (54). Ugolkov et al (18) reported that OCT4 nuclear expression was markedly associated with benign prostatic lesions, but not prostate cancer. In the present study, OCT4 expression was found in the prostate cancer and non-cancerous glandular cells; however, differences were observed in its expression between prostate cancer and non-cancerous glands. Although, these differences were not as marked as those observed in NANOG expression.

One notable observation in the current study was that prostate cancer cells expressing NANOG and OCT4 were also positive for HIF-1 $\alpha$ reactivity. Hypoxia-regulated genes are mediated by the HIF-1 complex composed of a heterodimeric pair of HIF- $1 \alpha$ and $-1 \beta(28,29)$, and HIF- $1 \alpha$ is an important transcription factor in prostate carcinogenesis, which suggests that HIF-1 $\alpha$ may be a potential prognostic biomarker in the proteomic assessments of prostate cancers $(55,56)$. Additionally, HIF-1 $\alpha$ induces human ES cell markers, such 
as NANOG $(14,30,31)$, OCT4 $(14,30,31)$ and CD133 (32), in cancer cells. The findings of the current study showing the coexpression of NANOG, OCT4 and HIF-1 $\alpha$ support these studies. However, a slightly positive reaction or null of CD133 in cancer cells was observed. The reason for this was unknown; although, a strong correlation was identified between NANOG and HIF-1 $\alpha$ expression, which may suggest that NANOG and HIF-1 $\alpha$ co-operate in prostate carcinogenesis.

The results of this study showed that of the four CSC markers examined (NANOG, OCT4, CD133 and NESTIN), NANOG was intensively expressed in prostate cancer. In addition, HIF-1 $\alpha$ was coexpressed in cancer cells. These findings suggest that NANOG, in conjunction with HIF-1 $\alpha$, may be important in prostate carcinogenesis. In addition, the immunohistochemical expression of NANOG may present as a biomarker for investigating the pathobiology of prostate cancer.

\section{Acknowledgements}

The authors would like to thank Dr Kohei Kawaguci, Dr Osamu Ueki and Mr. Hideaki Nishida for providing the biopsy samples. This study was supported, in part, by a grant (2010) from the Hokkoku Cancer Research Promotion Foundation and a Grant for Alumni Research from the Kanazawa Medical University (grant no. AR2012-01).

\section{References}

1. Jemal A, Siegel R, Ward E, Hao Y, Xu J, Murray T and Thun M: Cancer statistics, 2008. CA Cancer J Clin 58: 71-96, 2008.

2. Matsuda T, Marugame T, Kamo K, Katanoda K, Ajiki W and Sobue T: Cancer incidence and incidence rates in Japan in 2002: based on data from 11 population-based cancer registries. Jpn J Clin Oncol 38: 641-648, 2008.

3. Nonn L, Ananthanarayanan V and Gann PH: Evidence for field cancerization of the prostate. Prostate 69: 1470-1479, 2009.

4. Al-Hajj M, Wicha MS, Benito-Hernandez A, Morrison SJ and Clarke MF: Prospective identification of tumorigenic breast cancer cells. Proc Natl Acad Sci USA 100: 3983-3988, 2003.

5. Collins AT, Berry PA, Hyde C, Stower MJ and Maitland NJ: Prospective identification of tumorigenic prostate cancer stem cells. Cancer Res 65: 10946-10951, 2005.

6. O'Brien CA, Pollett A, Gallinger S and Dick JE: A human colon cancer cell capable of initiating tumour growth in immunodeficient mice. Nature 445: 106-110, 2007.

7. Gu G, Yuan J, Wills M and Kasper S: Prostate cancer cells with stem cell characteristics reconstitute the original human tumor in vivo. Cancer Res 67: 4807-4815, 2007.

8. Miki J, Furusato B, Li H, Gu Y, Takahashi H, Egawa S, Sesterhenn IA, McLeod DG, Srivastava S and Rhim JS: Identification of putative stem cell markers, CD133 and CXCR4, in hTERT-immortalized primary nonmalignant and malignant tumor-derived human prostate epithelial cell lines and in prostate cancer specimens. Cancer Res 67: 3153-3161, 2007.

9. Chambers I, Colby D, Robertson M, Nichols J, Lee S, Tweedie S and Smith A: Functional expression cloning of Nanog, a pluripotency sustaining factor in embryonic stem cells. Cell 113: 643-655, 2003.

10. Mitsui K, Tokuzawa Y, Itoh H, Segawa K, Murakami M, Takahashi K, Maruyama M, Maeda M and Yamanaka S: The homeoprotein Nanog is required for maintenance of pluripotency in mouse epiblast and ES cells. Cell 113: 631-642, 2003.

11. Zhang S, Balch C, Chan MW, Lai HC, Matei D, Schilder JM, Yan PS, Huang TH and Nephew KP: Identification and characterization of ovarian cancer-initiating cells from primary human tumors. Cancer Res 68: 4311-4320, 2008.

12. Santagata S, Ligon KL and Hornick JL: Embryonic stem cell transcription factor signatures in the diagnosis of primary and metastatic germ cell tumors. Am J Surg Pathol 31: 836-845, 2007.

13. Gong C, Liao H, Guo F, Qin L and Qi J: Implication of expression of Nanog in prostate cancer cells and their stem cells. J Huazhong Univ Sci Technolog Med Sci 32: 242-246, 2012.
14. Ma Y, Liang D, Liu J, Axcrona K, Kvalheim G, Stokke T, Nesland JM and Suo Z: Prostate cancer cell lines under hypoxia exhibit greater stem-like properties. PLoS One 6: e29170, 2011.

15. Scholer HR, Hatzopoulos AK, Balling R, Suzuki N and Gruss P: A family of octamer-specific proteins present during mouse embryogenesis: evidence for germline-specific expression of an Oct factor. EMBO J 8: 2543-2550, 1989.

16. Boiani $M$ and Scholer HR: Regulatory networks in embryo-derived pluripotent stem cells. Nat Rev Mol Cell Biol 6: 872-884, 2005.

17. Monk M and Holding C: Human embryonic genes re-expressed in cancer cells. Oncogene 20: 8085-8091, 2001.

18. Ugolkov AV, Eisengart LJ, Luan C and Yang XJ: Expression analysis of putative stem cell markers in human benign and malignant prostate. Prostate 71: 18-25, 2011.

19. Mallanna SK and Rizzino A: Systems biology provides new insights into the molecular mechanisms that control the fate of embryonic stem cells. J Cell Physiol 227: 27-34, 2012.

20. Tysnes BB: Tumor-initiating and -propagating cells: cells that we would like to identify and control. Neoplasia 12: 506-515, 2010.

21. Till JE: Stem cells in differentiation and neoplasia. J Cell Physiol Suppl 1: 3-11, 1982.

22. Grosse-Gehling P, Fargeas CA, Dittfeld C, Garbe Y, Alison MR, Corbeil D and Kunz-Schughart LA: CD133 as a biomarker for putative cancer stem cells in solid tumours: limitations, problems and challenges. J Pathol 229: 355-378, 2013.

23. Missol-Kolka E, Karbanova J, Janich P, Haase M, Fargeas CA, Huttner WB and Corbeil D: Prominin-1 (CD133) is not restricted to stem cells located in the basal compartment of murine and human prostate. Prostate 71: 254-267, 2011.

24. Lendahl U, Zimmerman LB and McKay RD: CNS stem cells express a new class of intermediate filament protein. Cell 60: 585-595, 1990.

25. Ishiwata T, Matsuda $Y$ and Naito Z: Nestin in gastrointestinal and other cancers: effects on cells and tumor angiogenesis. World J Gastroenterol 17: 409-418, 2011.

26. Kleeberger W, Bova GS, Nielsen ME, Herawi M, Chuang AY, Epstein JI and Berman DM: Roles for the stem cell associated intermediate filament Nestin in prostate cancer migration and metastasis. Cancer Res 67: 9199-9206, 2007.

27. Sotomayor P, Godoy A, Smith GJ and Huss WJ: Oct4A is expressed by a subpopulation of prostate neuroendocrine cells. Prostate 69: 401-410, 2009.

28. Kimbro KS and Simons JW: Hypoxia-inducible factor-1 in human breast and prostate cancer. Endocr Relat Cancer 13: 739-749, 2006

29. Mabjeesh NJ and Amir S: Hypoxia-inducible factor (HIF) in human tumorigenesis. Histol Histopathol 22: 559-572, 2007.

30. Bao B, Ahmad A, Kong D, Ali S, Azmi AS, Li Y, Banerjee S, Padhye S and Sarkar FH: Hypoxia induced aggressiveness of prostate cancer cells is linked with deregulated expression of VEGF, IL- 6 and miRNAs that are attenuated by CDF. PLoS One 7: e43726, 2012.

31. Mathieu J, Zhang Z, Zhou W, Wang AJ, Heddleston JM, Pinna CM, Hubaud A, Stadler B, Choi M, Bar M, et al: HIF induces human embryonic stem cell markers in cancer cells. Cancer Res 71: 4640-4652, 2011.

32. Salnikov AV, Liu L, Platen M, Gladkich J, Salnikova O, Ryschich E, Mattern J, Moldenhauer G, Werner J, Schemme P, et al: Hypoxia induces EMT in low and highly aggressive pancreatic tumor cells but only cells with cancer stem cell characteristics acquire pronounced migratory potential. PLoS One 7: e46391, 2012.

33. Clark AT: The stem cell identity of testicular cancer. Stem Cell Rev 3: 49-59, 2007.

34. Cizkova D, Soukup T and Mokry J: Nestin expression reflects formation, revascularization and reinnervation of new myofibers in regenerating rat hind limb skeletal muscles. Cells Tissues Organs 189: 338-347, 2009.

35. Horst D, Kriegl L, Engel J, Kirchner T and Jung A: CD133 expression is an independent prognostic marker for low survival in colorectal cancer. Br J Cancer 99: 1285-1289, 2008.

36. Chambers I and Tomlinson SR: The transcriptional foundation of pluripotency. Development 136: 2311-2322, 2009.

37. Ben-Porath I, Thomson MW, Carey VJ, Ge R, Bell GW, Regev A and Weinberg RA: An embryonic stem cell-like gene expression signature in poorly differentiated aggressive human tumors. Nat Genet 40: 499-507, 2008. 
38. Ezeh UI, Turek PJ, Reijo RA and Clark AT: Human embryonic stem cell genes OCT4, NANOG, STELLAR, and GDF3 are expressed in both seminoma and breast carcinoma. Cancer 104: 2255-2265, 2005

39. Li L, Yu H, Wang X, Zeng J, Li D, Lu J, Wang C, Wang J, Wei J, Jiang $\mathrm{M}$ and Mo B: Expression of seven stem-cell-associated markers in human airway biopsy specimens obtained via fiberoptic bronchoscopy. J Exp Clin Cancer Res 32: 28, 2013

40. Luo W, Li S, Peng B, Ye Y, Deng X and Yao K: Embryonic stem cells markers SOX2, OCT4 and Nanog expression and their correlations with epithelial-mesenchymal transition in nasopharyngeal carcinoma. PLoS One 8: e56324, 2013.

41. Yin X, Li YW, Zhang BH, Ren ZG, Qiu SJ, Yi Y and Fan J: Coexpression of stemness factors Oct4 and Nanog predict liver resection. Ann Surg Oncol 19: 2877-2887, 2012.

42. English HF, Santen RJ and Isaacs JT: Response of glandular versus basal rat ventral prostatic epithelial cells to androgen withdrawal and replacement. Prostate 11: 229-242, 1987.

43. Lawson DA and Witte ON: Stem cells in prostate cancer initiation and progression. J Clin Invest 117: 2044-2050, 2007.

44. Hurt EM, Kawasaki BT, Klarmann GJ, Thomas SB and Farrar WL: CD44+ CD24(-) prostate cells are early cancer progenitor/stem cells that provide a model for patients with poor prognosis. Br J Cancer 98: 756-765, 2008.

45. Yu J, Vodyanik MA, Smuga-Otto K, Antosiewicz-Bourget J, Frane JL, Tian S, Nie J, Jonsdottir GA, Ruotti V, Stewart R, et al: Induced pluripotent stem cell lines derived from human somatic cells. Science 318: 1917-1920, 2007.

46. Pan $\mathrm{G}$ and Thomson JA: Nanog and transcriptional networks in embryonic stem cell pluripotency. Cell Res 17: 42-49, 2007.

47. Pereira L, Yi F and Merrill BJ: Repression of Nanog gene transcription by Tcf3 limits embryonic stem cell self-renewal. Mol Cell Biol 26: 7479-7491, 2006

48. Suzuki A, Raya A, Kawakami Y, Morita M, Matsui T, Nakashima K, Gage FH, Rodríguez-Esteban C and Izpisúa Belmonte JC: Maintenance of embryonic stem cell pluripotency by Nanog-mediated reversal of mesoderm specification. Nat Clin Pract Cardiovasc Med 3 (Suppl 1): S114-S122, 2006.
49. Chiou SH, Yu CC, Huang CY, Lin SC, Liu CJ, Tsai TH, Chou SH, Chien CS, Ku HH and Lo JF: Positive correlations of Oct-4 and Nanog in oral cancer stem-like cells and high-grade oral squamous cell carcinoma. Clin Cancer Res 14: 4085-4095, 2008.

50. Jeter CR, Badeaux M, Choy G, Chandra D, Patrawala L, Liu C, Calhoun-Davis T, Zaehres H, Daley GQ and Tang DG: Functional evidence that the self-renewal gene NANOG regulates human tumor development. Stem Cells 27: 993-1005, 2009.

51. Xu RH, Sampsell-Barron TL, Gu F, Root S, Peck RM, Pan G, Yu J, Antosiewicz-Bourget J, Tian S, Stewart R and Thomson JA: NANOG is a direct target of TGFbeta/activin-mediated SMAD signaling in human ESCs. Cell Stem Cell 3: 196-206, 2008.

52. Danielpour D: Functions and regulation of transforming growth factor-beta (TGF-beta) in the prostate. Eur J Cancer 41: 846-857, 2005.

53. Pesce M and Scholer HR: Oct-4: control of totipotency and germline determination. Mol Reprod Dev 55: 452-457, 2000.

54. Zangrossi S, Marabese M, Broggini M, Giordano R, D'Erasmo M, Montelatici E, Intini D, Neri A, Pesce M, Rebulla P and Lazzari L: Oct-4 expression in adult human differentiated cells challenges its role as a pure stem cell marker. Stem Cells 25: 1675-1680, 2007.

55. Lekas A, Lazaris AC, Deliveliotis C, Chrisofos M, Zoubouli C, Lapas D, Papathomas T, Fokitis I and Nakopoulou L: The expression of hypoxia-inducible factor-1alpha (HIF-1alpha) and angiogenesis markers in hyperplastic and malignant prostate tissue. Anticancer Res 26: 2989-2993, 2006.

56. Makarewicz R, Zyromska A and Andrusewicz H: Comparative analysis of biological profiles of benign prostate hyperplasia and prostate cancer as potential diagnostic, prognostic and predictive indicators. Folia Histochem Cytobiol 49: 452-457, 2011. 